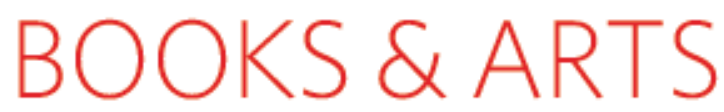

\title{
Coping with interesting times
}

\section{Unless we take action urgently, climate change could spell disaster for a wide range of living species.}

Climate Change and Biodiversity

edited by Thomas E. Lovejoy \& Lee Hannah

Yale University Press: 2005. 440 pp. \$65,

$€ 45$

\section{Paul Colinvaux}

A Chinese curse says: "May you live in interesting times." The 'interesting times' the Chinese had in mind were familiar stories from human history: battle, murder and sudden death, chaos, disease and famine. But the authors corralled by Tom Lovejoy and Lee Hannah talk of times even more 'interesting' than these: they discuss the grotesque climate changes of the greenhouse Earth. These are interesting enough for the chances of human happiness but are truly desperate for the survival of the remaining diversity of life on Earth. In the 24 chapters of Climate Change and Biodiversity, 66 authors suggest a little of what might be done to save something from the wreck. The book is written in the hope that policy-makers might read it, and it has been skilfully edited to that end by turning as much scientific prose as possible into plain English,

The brutal outline of what is happening is a twice-told tale. The atmosphere and continents are warming as we release carbon dioxide into the air through our habit of powering our society by oxidizing fossil carbon. Some of the first, most easily predictable, results are already apparent as the Arctic permafrost and glaciers melt. A rising concentration of carbon dioxide, a rising temperature and a consequent rising sea level have all been measured. These early-warning signs of what's to come are well known and have their own literature, so Lovejoy and Hannah offer just a few chapters on climate and modelling for those who need to play catch-up. Without profound changes in our energy systems, we are in for a few generations of misery, but as with other interesting times' we shall muddle through, forced to cope with the conditions. It is the rest of life on Earth that concerns the authors.

Climate is part of geography. The air is divided into great masses, much as the land is divided into continents, although the two maps are not congruent. But maps of the usual or seasonal positions of air masses over continents and maps of vegetation are congruent. Indeed, they are so congruent that the first climate maps were made by mapping vegetation on a continental scale and calling the result

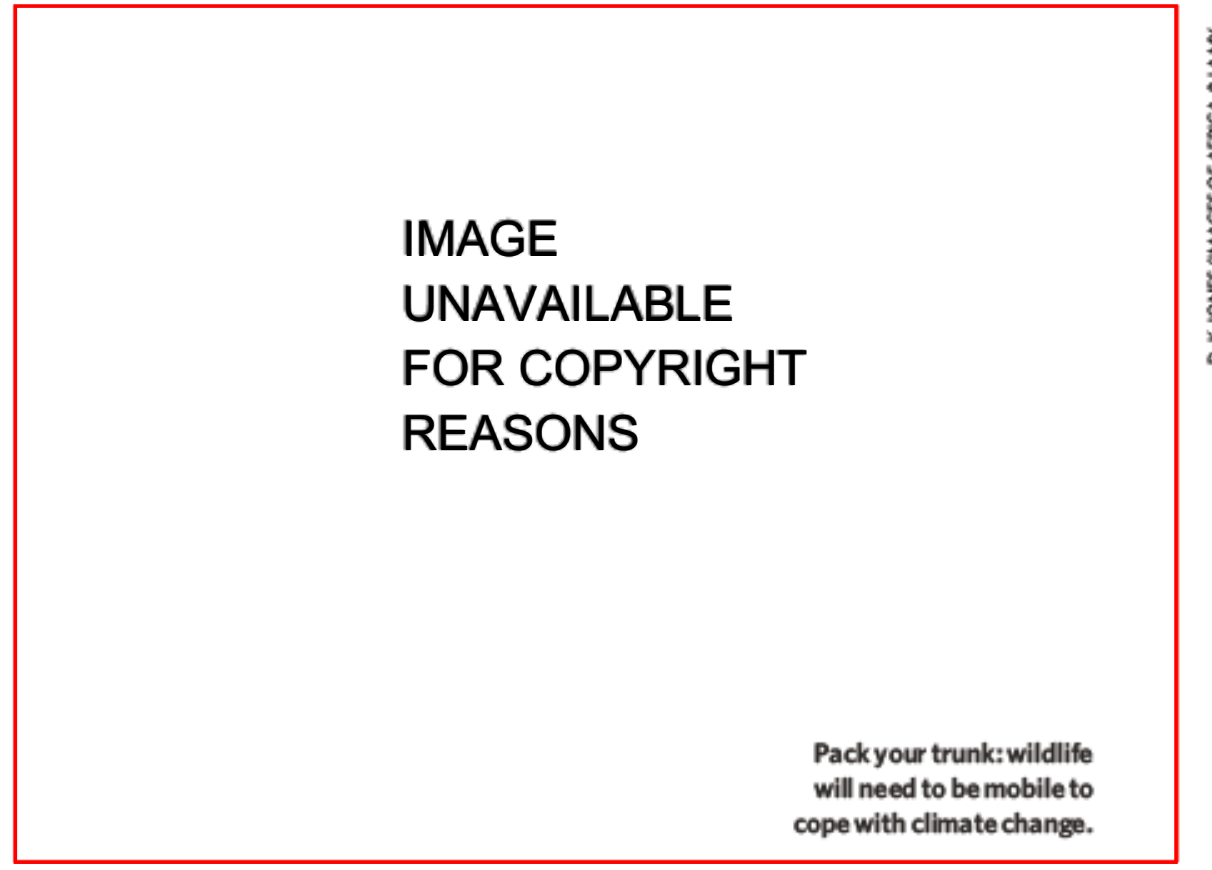

'climate.' Great patches of plants, large enough to be coloured in the family atlas, were called 'formations'. Later, ecologists complained that animals were being neglected and were probably as typical to the climate as were the plants. They named a terrestrial unit with characteristic climate a 'biome', a name that has stuck, even though it is a mere abstraction.

A conservationists' lament echoed in this book is that most nature reserves and conservation areas are now in the wrong places. Some, such as Yellowstone National Park, were set up on land that was little good for anything else; others were created to protect a good bit of a biome, or a place where the cuddly or the rare were known to live. But the greenhouse is moving the air masses, so the old places of refuge will be no use. What is to be done?

Strangely, palaeoecology comes to our rescue. We know from fossils, particularly from fossil pollen, how the plants of the great Pleistocene formations survived the repeated redrawing of the climate map of the ice-age Earth. Plants left the formations of their ancestors and dispersed to new habitats, or hung on in patches where the new climate was within the bounds of tolerance, or coexisted at the edges of old ranges with plant survivors of what was once an adjacent range.

Plants move as seeds, carried by winds or animals, whereas animals can move on their own. But they can all move, and they all do: none of them are forced to remain in what used to be a refuge or a relationship. The answer to the conservationist dilemma, then, is to let every refuge have an escape route. Conceive a world of scattered refuges in between patchworks of land parcels of mixed use: built-up areas, parks, houses with gardens, green strips on highways, windbreaks. Conservationists call this design the 'matrix' - a meaning in keeping withthe word's derivation from the Latin for 'womb'. If we concentrate on providing a good matrix between conservation areas, we just might solve the problem.

The politics will be difficult. Some of the book's authors pin their hopes on trying to stop us building the greenhouse. My own cynical view is that if the government of a great nation will not act to protect the livelihoods of its own citizens, it is unlikely to take political risks to defend a few animals and plants. Lovejoy and Hannah's book may well be the only kind of resource we have: an attempt to let those who have the power to act know what the intelligence system of science is saying, and that it should be believed. This is where the battle must be fought. Now we need some even more readable essays.

Paul Colinvaux is in the Marine Biological

Laboratory, 7 MBL Street, Woods Hole, Massachusetts 02543, USA.

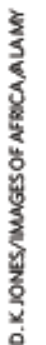

